\title{
Serum sodium disorders in patients with traumatic brain injury
}

This article was published in the following Dove Press journal:

Therapeutics and Clinical Risk Management

10 August 2011

Number of times this article has been viewed

\author{
Wellingson Silva Paiva \\ Douglas Alexandre França \\ Bezerra \\ Robson Luis Oliveira \\ Amorim \\ Eberval Gadelha Figueiredo \\ Wagner Malago Tavares \\ Almir Ferreira De Andrade \\ Manoel Jacobsen Teixeira \\ Intensive Care Unit, Division of \\ Neurosurgery, Hospital Das Clinicas, \\ University of São Paulo School \\ of Medicine, São Paulo, Brazil
}

Correspondence: Wellingson Paiva University of São Paulo, Eneas Aguiar Street N 255 Office 4080, São Paulo, Brazil 05403010

Tel +55 II 30697226

Fax +55 II 25486906

Email wellingsonpaiva@yahoo.com.br

\begin{abstract}
Sodium disorders are the most common and most poorly understood electrolyte disorders in neurological patients. The aim of this study was to determine the incidence of sodium disorders and its association with different traumatic brain injuries. This prospective study was conducted in 80 patients diagnosed with moderate and severe traumatic brain injuries. All patients underwent cerebral computed tomography. Incidence of sodium disorders, presence of injuries in the first computed tomography after traumatic brain injury, and level of consciousness were analyzed. Patients that presented other potential causes of sodium disorders and systemic trauma were excluded from the study. The incidence of sodium disturbances was 45\%: 20 patients presented hypernatremia and 16 hyponatremia. Refers to all patients with sodium disturbances 53\% were detected in the first sample. We recorded at least one measurement $<125 \mathrm{mEq} / \mathrm{L}$ in $50 \%$ of the patients with hyponatremia. A greater incidence of sodium disorders was found in patients with subdural, intracerebral hematoma and with diffuse axonal injury. The incidence of sodium disorders among the patients with diffuse lesions was greater than in the group of patients with brain contusion $(P=0.022)$. The incidence of sodium disorders is higher in patients with diffuse traumatic brain injuries. No association was found between focal lesions and proportion of sodium disorders.
\end{abstract}

Keywords: brain trauma, hypernatremia, hyponatremia

\section{Introduction}

Serum sodium disorders are the most common and probably the most poorly understood electrolyte disorders in neurological disease. ${ }^{1,2}$ The disturbance may manifest as hypernatremia or hyponatremia. Hypernatremia usually occurs in the syndrome of diabetes insipidus, whereas hyponatremia develops as a syndrome of inappropriate secretion of antidiuretic hormone or cerebral salt-wasting syndrome. ${ }^{2,3}$ It is well established that the outcomes of a traumatic brain injury (TBI) depend substantially on the homeostasis disorders following the trauma. Hyponatremia is a common electrolyte disorder encountered in patients in the neurosurgical intensive care unit (ICU). ${ }^{1,4}$

The majority of recent studies that address the problem focus on the analysis of the neuroendocrinological mechanisms involved and therapeutic aspects. ${ }^{4} \mathrm{~A}$ few recent studies have been conducted on the prevalence, risk factors, associations with other conditions and parameters, and the results in the different types of cerebral illness. The majority of the studies that address these aspects deal with subarachnoid hemorrhage. ${ }^{5,6}$ Despite the importance of sodium disorders in TBI without systemic lesions in clinical practice, the incidence has been little studied. In this paper, the authors' aim was to determine the prevalence of sodium disorders such as hypernatremia and hyponatremia and their association with TBI in stable patients in a university hospital with a level I trauma center. 
This study was approved by the ethical committee of Hospital Das Clinicas, University of São Paulo School of Medicine, São Paulo, Brazil.

\section{Methods}

This prospective study was conducted in 80 consecutive patients diagnosed with TBI who were managed in 1 year and were hospitalized in the surgical ICU of the authors' hospital. All patients underwent neurosurgical examination, cervical spine and plain chest radiography, and cerebral computed tomography (CT). Patients underwent CT scans on two occasions: on hospital admission after resuscitation and within 12 hours after the first tomography. Hypertonic saline solution was not used in our cases, and no protocols with hypertonic saline solution for care in a rescue unit were adopted in Brazil. During this period, 2112 trauma patients were treated and, of these, 493 had moderate or severe TBI. Excluded from the study were those with prior sodium disorders or receiving diuretics (11 patients), 384 patients with associated systemic trauma (abdominal and orthopedic trauma; since these lesions often involve blood loss and need resuscitation with saline solution), and patients with moderate TBI not managed in the ICU (18 patients). After hospital admission with resuscitation by advanced trauma life support (ATLS) protocol, all patients with TBI and normal hemodynamic status were admitted to ICU and were included in this study. They did not receive diuretics and were free from renal or other endocrine diseases. Patients that presented other potential causes of sodium disorders and systemic trauma were excluded from the study. Sodium disorders were considered as disorders presenting at least one serum sodium detection $<130 \mathrm{mEq} / \mathrm{L}$ or $>145 \mathrm{mEq} / \mathrm{L}$ in the period from hospital admission (first sample collected in the emergency room during resuscitation) to 30 days (minimum follow-up) after TBI. In all patients, a standard blood sample was taken (collected directly from a peripheral vein in the arm or leg).

Patients who were hypo- or hypernatremic on admission, as well as those who developed sodium disorders during hospitalization, were included in the study. In patients with abnormal sodium, a blood sample was collected every day until correction of sodium and after that at least one blood sample per week during the first month after trauma. Decisions regarding the management of sodium disorders were left to the physicians responsible and were not influenced by the study. For all measurements, an AVL 988-4 Electrolyte Analyzer (AVL Scientific Co, Roswell, GA) was used.
The characteristics of the patients analyzed were as follows: incidence of sodium disorders, presence of injuries in the first CT scan of the skull after TBI (all scans were evaluated by two team members trained in CT evaluation), and level of consciousness according to the Glasgow coma scale (GCS). ${ }^{7}$ Only severe (GCS $<9$ ) and moderate (GCS 9-13) TBI cases were considered in the study. The diagnostic criteria for diffuse injury was used in persistent comatose patients (more than 6 hours) and no focal lesions greater than $25 \mathrm{~cm}^{3}$ as described by Marshall et al. ${ }^{8}$ The great majority $(81.3 \%)$ of the patients were male. The average age was 35 years, with substantial variation (3-87). A $P$ value of less than 0.05 was considered significant. The statistical analyses were performed using SigmaStat ${ }^{\circledR}$ (Jadel Inc, Brandon, FL) software, applied within each subgroup analysis using chi-square test to compare proportions. The study protocol was approved by the ethics committee of the authors' hospital.

\section{Results}

We recorded traumatic subarachnoid hemorrhage in 53\% of the patients, $31 \%$ from acute subdural hematoma, $22 \%$ from acute epidural hematoma, and $7.5 \%$ with diffuse axonal injury with normal CT. We observed no ventricular hemorrhage. Of the 80 patients, 42 received surgical treatment. The surgical treatments were as follows: 3 patients for intracranial pressure monitoring and 39 patients undergoing hematoma removal and/or evacuation of the contused brain. The prevalence of sodium disorders was 45\%: 20 patients presented with hypernatremia and 16 with hyponatremia. Of these, $53 \%$ had already been detected in the first sample. In the early evolution of the condition, another 19 cases presented sodium disorders. Hypernatremia, occurring in $25 \%$ of the cases, was more prevalent than hyponatremia, as in the first sample (Table 1). The average time of the first detection was 5 days for hypernatremia and 6 days for the hyponatremia. In terms of severity, 17 patients presented at least one measurement $>150 \mathrm{mEq}(85 \%$ of the patients with hypernatremia findings). Of these, 5 (30\%) occurred

Table I Incidence of sodium disorders according to detection time

\begin{tabular}{llll}
\hline Detection time & Hypernatremia & Hyponatremia & Total \\
\hline First sample (in ER) & $9(11 \%)$ & $8(10 \%)$ & $17(21 \%)$ \\
Detection in ICU & $11(14 \%)$ & $8(10 \%)$ & $19(24 \%)$ \\
Total & $20(25 \%)$ & $16(20 \%)$ & $36(45 \%)$ \\
\hline
\end{tabular}

Abbreviations: $\mathrm{ER}$, emergency room; ICU, intensive care unit. 
in the first blood analysis and 12 during the evolution. As an initial treatment, all 16 patients who presented with hyponatremia were given sodium supplementation therapy. However, 3 of these 16 patients (18.7\%) presented recurrence of hyponatremia, which required sodium supplementation therapy again in the course of time. Sodium excretion and pituitary hormone levels were not measured in these patients. At least one measurement $<125 \mathrm{mEq} / \mathrm{L}$ was found in eight patients ( $50 \%$ of the patients with hyponatremia findings), all occurring during the evolution. No differences between the incidences of disorders according to sex and age were observed. The patients with subdural, intracerebral hematoma and those with diffuse axonal injury had a greater incidence of sodium disorders, but these differences were not statistically significant (Table 2). The incidence of sodium disorders among the patients with diffuse lesions was greater than in the group of patients with intracerebral hematoma $(P=0.022)$ (Table 3).

\section{Discussion}

The incidence of sodium disorders was high in this study, and the results were similar to those of other series. ${ }^{9,10}$ The results of this study showed that a large number of patients presented sodium disorders after each type of TBI but no association with specific intracranial lesions was identified. The substantial rate of detection of disorders on the day of admission suggests severe brain lesions. Hypernatremia was the most frequent disorder in the authors' patients.
The mortality rates in head-injured patients with hypernatremia are higher than rates in such patients with normal sodium concentrations. ${ }^{11}$ Once the serum sodium concentration is elevated, it can result in remarkable brain swelling. Since the amount of the infusion volume is controlled manually in head-injured patients, unexpected loss of free water as a result of excretion of hypotonic urine can induce hypernatremic dehydration. Furthermore, losses of water can decrease renal plasma flow and renal filtration rates, resulting in aggravation of the hypernatremia. ${ }^{11}$ Hyponatremia was detected in $20 \%$ of cases. Arieff et al found that the acute onset of severe hyponatremia following TBI was associated with a poor neurological outcome or death after a sudden onset of seizures, followed by coma, apnea, and brainstem compression. ${ }^{12}$

In a retrospective cohort study, Maggiore et al verified that hypernatremia was common, occurring in 51.5\% of patients for $31 \%$ of the duration of their ICU stay. ${ }^{13}$ Hypernatremia was associated with a threefold increase in hazard of ICU death, even after adjustment for baseline risk. In the present study, the authors verified hypernatremia in $25 \%$ of the patients; of these, $53 \%$ had already been detected in the first sample.

Horn and Glenn screened patients with severe head injury and found that $20 \%$ suffered from one or more hormone disturbances. ${ }^{14}$ The cause of sodium disorders are diverse and the associated risk of morbidity vary widely. Therefore, early diagnosis and effective treatment of hyponatremia is critical for hyponatremic patients

Table 2 Incidence of sodium disorders according to brain injury

\begin{tabular}{|c|c|c|c|c|}
\hline $\begin{array}{l}\text { Intracranial lesion and } \\
\text { sodium disorders }\end{array}$ & Total N (\%) & Prevalence N (\%) & Odds ratio & $\mathrm{Cl} 95 \%$ \\
\hline \multicolumn{5}{|l|}{ ASDH } \\
\hline No & $55(68.75)$ & $24(43.6)$ & 1.0 & \\
\hline Yes & $25(31.25)$ & $12(48.0) \times 2: 0.13$ p: 0.71 & 1.01 & $0.4-2.5$ \\
\hline \multicolumn{5}{|l|}{ AEDH } \\
\hline No & $62(77.5)$ & $28(45.2)$ & 1.0 & \\
\hline Yes & I8 (22.5) & $8(44.4) \times 2: 0.004$ p: 0.95 & 1.03 & $0.3-3.5$ \\
\hline \multicolumn{5}{|l|}{ ICH } \\
\hline No & $68(85)$ & $30(44.1)$ & 1.0 & \\
\hline Yes & $12(15)$ & $6(50) \times 2: 0.14 p: 0.7$ & 0.8 & $0.3-3.5$ \\
\hline \multicolumn{5}{|l|}{ TSAH } \\
\hline No & $37(46.2)$ & $16(43.2)$ & 1.0 & \\
\hline Yes & $43(53.7)$ & $17(39.2) \times 2: 1.5 \mathrm{p:} 0.2$ & 0.6 & $0.2-1.4$ \\
\hline \multicolumn{5}{|l|}{ DAI } \\
\hline No & $74(92.5)$ & $42(56.7)$ & 1.0 & \\
\hline Yes & $6(7.5)$ & $4(66.7) \times 2: 0.35 p: 0.55$ & 1.7 & $0.3-10$ \\
\hline
\end{tabular}

Abbreviations: ASDH, acute subdural hematoma; AEDH, acute epidural hematoma; TSAH, traumatic subarachnoid hemorrhage; ICH, intracerebral hematoma; DAl, diffuse axonal lesion; $\mathrm{Cl}$, confidence interval; $\mathrm{N}$, number. 
Table 3 Incidence of sodium disorders, comparing diffuse lesions with cerebral hematoma

\begin{tabular}{lll}
\hline Brain injury & \multicolumn{2}{l}{ Presence of sodium disorders $^{\mathbf{a}}$} \\
\cline { 2 - 3 } & Yes & No \\
\hline ICH & $50 \%$ & $50 \%$ \\
DAI & $66.7 \%$ & $33.3 \%$ \\
\hline
\end{tabular}

Note: ${ }^{a} P=0.022$.

Abbreviations: DAl, diffuse axonal lesion; ICH, intracerebral hematoma.

with intracranial disease. Neurological dysfunction is the principal manifestation of hyponatremia, which may be exacerbated by other disease processes or underlying conditions, especially in those patients in whom a pathological condition is located intracranially. ${ }^{10}$ The high rate of serious alterations during the evolution suggests the possible occurrence of associated neuroendocrinological conditions such as diabetes insipidus, syndrome of inappropriate secretion of antidiuretic hormone, and cerebral salt wasting. The mechanism by which an intracranial disease leads to the occurrence of the syndrome has yet to be fully elucidated. There were no patients with diabetes insipidus in the present study. Because there was insufficient data on pituitary function and sodium excretion in patients, although syndrome of inappropriate antidiuretic hormone hypersecretion is the most common cause of hyponatremia, ${ }^{15}$ the cause of their hyponatremia remains unclear.

Hyponatremia may also be caused by the activity of the brain natriuretic factor (BNF), probably secreted by the thalamus, exerting an action identical to that of the hormone secreted by the atrial cardiocytes. ${ }^{16,17} \mathrm{BNF}$ is a potent diuretic, natriuretic, vasodilating agent, and an inhibitor of the secretion of aldosterone, renin, and vasopressin..$^{18-20}$ It also decreases plasma volume. Increased BNF is most commonly found in patients with subarachnoid hemorrhage or hemorrhage at the base of the brain or in the third ventricle..$^{21,22}$ BNF was not measured in this study because the authors did not have the appropriate equipment. In the patients studied, there was no special pathological substrate to induce the effects of BNF, except for diffuse brain edema present in the majority of patients. The incidence of sodium disorders was high in study patients with diffuse TBI. No association was found between specific types of TBI and the proportion of sodium disorders, but the incidence of sodium disorders was greater in diffuse injury than in intracerebral hematoma. Disturbances of plasma sodium concentration warrant close attention in patients with craniocerebral injuries to allow timely and appropriate therapeutic intervention and prevent possible complications that may exacerbate conditions and eventually lead to death.
The authors believe that the selected sample allowed the exclusion of confounding variables to restrict head trauma without other injuries, but this deviated slightly from clinical reality. The authors' also believe that further studies with larger numbers of patients and blind comparison can respond to questions not answered in this study.

\section{Disclosure}

The authors report no conflicts of interest in this work.

\section{References}

1. Belvins LS, Wand GS. Diabetes insipidus. Crit Care Med. 1992; 20:69-79.

2. Doc ZIT, Bende J, Huska E, Kiss J. Syndrome of inappropriate secretion of antidiuretic hormone after subarachnoid hemorrhage. Neurosurgery. 1981;9:394-397.

3. Harrigan MR. Cerebral salt wasting syndrome: a review. Neurosurgery. 1996;38:152-160.

4. Coenraad MJ, Meinders AE, Vandenbroucke JP, et al. Causes of hyponatremia in the Departments of Internal Medicine and Neurosurgery. Eur J Intern Med. 2003;14(5):302-309.

5. Sherlock M, O'Sullivan E, Agha A, et al. The incidence and pathophysiology of hyponatremia after subarachnoid haemorrhage. Clin Endocrinol (Oxf). 2006;64(3):250-254.

6. Revilla-Pacheco FR, Herrada-Pineda T, Loyo-Varela M, ModianoEsquenazi M. Cerebral salt wasting syndrome in patients with aneurysmal subarachnoid hemorrhage. Neurol Res. 2005;27(4):418-422.

7. Teasdale G, Jannett B. Assessment of coma and impaired consciousness, a practical scale. Lancet. 1974;2:81-84.

8. Marshall LF, Marshall SB, Klauber MR, van Berkum Clark RN. A new classification of head injury based on computerized tomography. J Neurosurg. 1991;75(Suppl):14-20.

9. Donati-Genet PC, Dubuis JM, Girardin E. Acute symptomatic hyponatremia and cerebral salt wasting after head injury: an important clinical entity. J Pediatr Surg. 2001;36:1094-1097.

10. Sterns RH. Severe symptomatic hyponatremia: treatment and outcome. A study of 64 cases. Ann Int Med. 1987;107(5):656-664.

11. Mizobata Y, Yokota J, Matsuoka T, Horikawa H, Nakai K, Fukuda A. Volume supplementation with iso-sodium solution prevents hypernatremia after head injury. J Trauma. 2001;50(5):871-877.

12. Arieff AI, Ayus JC, Fraser CL. Hyponatremia and death or permanent brain damage in healthy children. BMJ. 1992;304:1218-1222.

13. Maggiore U, Picetti E, Antonucci E, et al. The relation between the incidence of hypernatremia and mortality in patients with severe traumatic brain injury. Crit Care. 2009;13:R110.

14. Horn LJ, Glenn MB. Update in pharmacology: pharmacology interventions in neuroendocrine disorders following traumatic brain injury, part two. J Head Trauma Rehabil. 1982;3:86-89.

15. Sherlock M, O'Sullivan E, Agha A, et al. Incidence and pathophysiology of severe hyponatremia in neurosurgical patients. Postgrad Med J. 2009;85(1002):171-175.

16. Sudoh T, Kangawa K, Minamino N, Matsuo H. A new natriuretic peptide in porcine brain. Nature. 1988;332:78-81.

17. Mukoyama M, Nakao K, Hosoda K, et al. Brain natriuretic peptide as a novel cardiac hormone in humans. J Clin Invest. 1991;87:1402-1412.

18. Goldsmith MF. Atrial peptide study proceeds apace. JAMA. 1987; 257:287.

19. Richards AM, Nicholls MG, Espiner EA, et al. Effects of alfa-human atrial natriuretic peptide in essential hypertension. Hypertension. 1985; 7:812-817.

20. Taikkanen I, Fyhrequist F, Metsarnine K, et al. Plasma atrial natriuretic peptide in normal man. J Clin Invest. 1986;77:734-742. 
21. Wijdicks EFM, Ropper AH, Hunnicutt EJ. Atrial natriuretic factor and salt wasting after aneurysmal subarachnoid hemorrhage. Stroke. 1991; 22:1519-1524.
22. Diringer MN, Lim JS, Kirch JR, et al. Suprasellar and intraventricular blood predict elevated plasma atrial natriuretic factor in subarachnoid hemorrhage. Stroke. 1991;22:577-581.

\section{Publish your work in this journal}

Therapeutics and Clinical Risk Management is an international, peerreviewed journal of clinical therapeutics and risk management, focusing on concise rapid reporting of clinical studies in all therapeutic areas, outcomes, safety, and programs for the effective, safe, and sustained use of medicines. This journal is indexed on PubMed Central, CAS,
EMBase, Scopus and the Elsevier Bibliographic databases. The manuscript management system is completely online and includes a very quick and fair peer-review system, which is all easy to use. Visit http://www.dovepress.com/testimonials.php to read real quotes from published authors.

Submit your manuscript here: http://www.dovepress.com/therapeutics-and-clinical-risk-management-journal 